\title{
Construction and Optimization of Recycling Logistics Network for Construction Waste
}

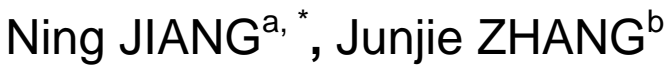 \\ ${ }^{1}$ Department of Business Administration, Qingdao Vocational and Technical College of Hotel \\ Management, Qingdao, 266100, China \\ aemail:qdjn202@163.com, bemail:zhangjunjie98@163.com
}

\begin{abstract}
Keywords: Construction Waste, Reverse Logistics, Recycling Network, Construction and Optimization
\end{abstract}

\begin{abstract}
Project construction is one of the most important economic activities. How to disposal construction waste is an urgent issue in the management of city. The traditional method is simple landfill, not only occupy the land, causing environmental pollution, but also waste a lot of resources which can be rational recycling. In this paper, considering the establishment of a reasonable reverse logistics network for construction waste to achieve the recycling, minimize the total cost such as network facilities investment, operation cost, transportation cost and other related costs.
\end{abstract}

\section{Introduction}

Construction waste refers to dregs, concrete block, a small amount of steel, wood and other wastes generated in the process of construction, is a kind of recyclable resources [1-2]. The implementation of recycling requires appropriate logistics network support, including the number and position of facilities such as recycling center, detection processing center, distribution center, building materials suppliers etc. Rational design of recycling network, determines the effectiveness of waste recycling. This paper considers construction of reverse logistics based on the existing building materials logistics network, and through an example to verify the feasibility and effectiveness of the model.

\section{Description of the Problem}

Suppose there is a construction waste reverse network, including waste recycling center, detection processing center, regenerative machining center three kinds of logistics facilities. After recycling center classification, construction waste inspected qualified in the detection processing center can directly be shipped to distribution center to sales; waste detection renewable can be shipped to regenerative machining center for further processing; unqualified will be waste disposal [3][4]. Flow chart of reverse recycling network as shown in Fig. 1.

In the construction of waste reverse logistics network based on existing building materials logistics network, the original building materials suppliers (or distribution center) can be used as regenerative machining center (or recycling center), or you can create some new.

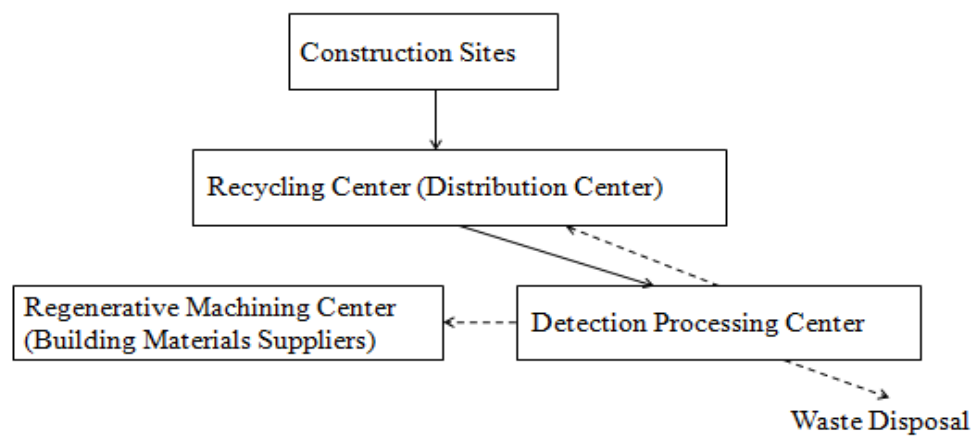

Fig.1. Flow chart of reverse recycling network 


\section{Model Establishment}

The Model Assumptions.(1)The cost of transportation and traffic volume between facilities are a linear relationship, correlation processing costs about recycling center, detection processing center and regenerative machining center are a linear function of the amount of processing.

(2)Waste recycling, the facilities processing capacity, infrastructure investment costs, unit operation variable costs, recycling classification and detection processing costs, as well as transportation cost between facilities and the disposal cost is determined.

(3)Because the operation variable cost relates to the facilities, so introduce an index of $\theta(0<\theta \leq 1)$, to consider the scale economy of facilities.

(4)Construction waste inspection qualified can directly be shipped to distribution center to sales; waste detection renewable can be shipped to regenerative Machining center to process; unqualified will be waste disposal, waste disposal rate is $\mu$.

(5)Considering material loss during transportation, thereby introduce the material loss factor $\alpha$, pay the cost per unit of material loss is indicated by $C$.

(6)The recycling center and detection processing center exists absorption rate of construction waste, respectively represented by the factor $r_{1}$ and $r_{2}$.

(7)Alternative address about recycling center, detection processing center or regenerative machining center is known.

(8)The new regenerative machining center or expansion building materials suppliers are willing to accept the recycled materials as much as possible.

The Mathematical Model. Model Symbol. $H$ represents a collection of construction sites, $h$ in H; $I$ represents a collection of recycling center (or expansion distribution center) , $i$ in $I$; $J$ represents a collection of detection processing center, $j$ in $J ; K$ represents a collection of regenerative machining center (or expansion building materials suppliers), $k$ in $K$.

The Parameters In The Model. $A_{\mathrm{h}}$ represents the recycling amount of construction waste; MAX- $U_{\mathrm{i}}$ represents the maximum recycling amount of new recycling center or expansion distribution center $i$; MAX $-V_{\mathrm{j}}$ represents the maximum treatment capacity of new detection processing center $j$; MIN-Wk represents the minimum processing ability on construction waste of new regenerative machining center or extension of building materials supplier $k$; $T C_{h i}$ represents the unit cost of transportation from construction sites $\mathrm{h}$ to recycling center $i$; $T C_{\mathrm{ij}}$ represents the unit cost of transportation from $i$ to detection processing center $j$; $T C_{\mathrm{jk}}$ represents the unit cost of transportation from $\mathrm{j}$ to regenerative machining center $k ; C_{\mathrm{i}}$ represents the infrastructure investment costs of recycling center $i$; $C_{\mathrm{j}}$ represents the infrastructure investment costs of detection processing center $j ; C_{\mathrm{k}}$ represents the infrastructure investment costs of regenerative machining center $k$; $O C_{\mathrm{i}}$ represents the unit processing costs of recycling center $i$; $O C_{\mathrm{j}}$ represents the unit testing costs of detection processing center $j ; L C_{\mathrm{j}}$ represents the unit disposal costs of detection processing center $j$; $O C_{\mathrm{k}}$ represents the unit cost of further processing of detection processing center $j ; V_{\mathrm{i}}$ represents the Coefficient of unit cost changes of recycling center $i$; $V_{\mathrm{j}}$ represents the Coefficient of unit cost changes of detection processing center $j$; $V_{\mathrm{k}}$ represents the Coefficient of unit cost changes of regenerative machining center $k$; $C_{\mathrm{c}}$ represents per unit material loss for the cost; $N_{1}, N_{2}, N_{3}$ represent the maximum number of establishing recycling center, detection processing center and regenerative machining center respectively; $r_{1}$ represents the construction waste absorption rate of recycling center; $r_{2}$ represents the construction waste absorption rate of detection processing center.

The Decision Variables. $M_{\mathrm{hi}}$ represents the number of waste from construction sites $\mathrm{h}$ to recycling center $i ; X_{\mathrm{ij}}$ represents the number of waste from recycling center $i$ to detection processing center $j ; Y_{\mathrm{jk}}$ represents the number of waste from detection processing center $j$ to regenerative machining center $k ; Z_{j i}$ represents the number of waste from detection processing center $j$ to distribution center $i$; $P_{\mathrm{i}}$ represents the turnover of construction waste in the new recycling center $i$ or expansion distribution center $i$; $Q_{\mathrm{j}}$ represents the turnover of construction waste in the new detection processing center $j$; $R_{\mathrm{k}}$ represents the turnover of construction waste in 
the new regenerative machining center $k$ or expansion building material suppliers $k ; D_{\mathrm{i}}$ is a $0 \sim 1$ variable, indicating whether the establishment of a recycling center in the $i$, is 1 , otherwise 0 ; $E_{\mathrm{j}}$ is a $0 \sim 1$ variable, indicating whether the establishment of a detection processing center in the $j$, is 1 , otherwise $0 ; \quad F_{k}$ is a $0 \sim 1$ variable, indicating whether the establishment of a regenerative machining center in the $k$, is 1 , otherwise 0 ;

\section{The Objective Function.}

$$
\begin{aligned}
& \min f=\sum_{h \in H} \sum_{i \in I} T C_{h i} M_{h i}+\sum_{i \in I} \sum_{j \in J} T C_{i j} X_{i j}+\sum_{j \in J} \sum_{k \in K} T C_{j k} Y_{j k}+\sum_{j \in J} \sum_{i \in I} T C_{j i} Z_{j i}+\sum_{i \in I} O C_{i} P_{i}+\sum_{j \in J} O C_{j} Q_{j}+\sum_{k \in K} O C_{k} R_{k}+\sum_{j \in J} \mu Q_{j} L C_{j}+ \\
& \sum_{i \in I} \alpha P_{i} C_{c}+\sum_{j \in J} \alpha Q_{j} C_{c}+\sum_{i \in I} V_{i} P_{i}^{\theta}+\sum_{j \in J} V_{j} Q_{j}^{\theta}+\sum_{k \in K} V_{k} R_{k}^{\theta}+\sum_{i \in I} C_{i} D_{i}+\sum_{j \in J} C_{j} E_{j}+\sum_{k \in K} C_{k} F_{k}
\end{aligned}
$$

The Constraint Conditions.

$$
\begin{aligned}
& \sum_{i \in I} M_{h i}=r_{1}(1-\alpha) A_{h}, h \in H \\
& \sum_{j \in J} X_{i j}=r_{2}(1-\alpha) \sum_{i \in I} M_{h i}, h \in H \\
& \sum_{j \in J} Y_{j k}+\sum_{j \in J} Z_{j i}=(1-\alpha)(1-\mu) \sum_{j \in J} X_{i j}, i \in I, k \in K \\
& \sum_{i \in I} M_{h i} \leq M A X-U_{i}, h \in H \\
& \sum_{j \in J} X_{i j} \leq M A X-V_{j}, i \in I \\
& \sum_{k \in K} Y_{j k} \geq M I N-W_{k}, j \in J \\
& \sum_{i \in I} M_{h i}=P_{i}, h \in H \\
& \sum_{j \in J} X_{i j}=Q_{j}, i \in I \\
& \sum_{k \in K} Y_{j k}=R_{k}, j \in J \\
& \sum_{i \in I} D_{i} \leq N_{1} \\
& \sum_{j \in J} E_{j} \leq N_{2} \\
& \sum_{k \in K} F_{k} \leq N_{3} \\
& M_{h i}, X_{i j}, Y_{j k}, Z_{j i} \geq 0, h \in H, i \in I, j \in J, k \in K \\
& D_{i}, E_{j}, F_{k}=0 o r 1, i \in I, j \in J, k \in K
\end{aligned}
$$

In the model, the objective function (1) expressed the minimum total cost of transportation cost between facilities, construction waste treatment cost, fixed investment cost, operation variable costs, waste disposal cost and material loss cost. Type (2) to type (4) is the flow balance constraints, type (5) to type (7) is the facilities processing capacity constraints, type (8) to type (10) represents the circulation and handling capacity of each node is equal, type (11) to type (13) is the new facilities quantitative restrictions. The above problem is a capacitated network location problem, whose model is a mixed integer programming model (MILP), can be solved by using the software Lingo.

\section{Simulation Examples}

There are 6 construction engineering buildings, 5 alternative locations of recycling center in a region, where $I_{1}, I_{2}$ can be considered to expand original distribution center; $I_{3}, I_{4}, I_{5}$ is a new candidate site; 3 alternative locations of detection processing center, $J_{1}, J_{2}$ and $J_{3} ; 4$ alternatives of regenerative machining center in which $K_{1}, \quad K_{2}$ construction material supplier, $K_{3}, K_{4}$ is a new candidate site. The material loss factor $\alpha=0.05$, the cost per unit of material loss $C_{\mathrm{c}}=10$, absorption rate of recycling center $r_{1}=80 \%$, absorption rate of detection processing center $r_{2}=60 \%$, waste disposal rate $\mu=0.2$, index $\theta=0.6$. Other relevant data as Table $1 \sim 10$ shown.

Using Lingo software to solve the above data, the results are shown in Fig.2. The minimum total cost is 626075; establish recycling center in the candidate $I_{1}, I_{2}, I_{5}$; detection processing center in $J_{2}, \quad J_{3}$; regenerative machining center in the candidate $K_{1}, K_{2}$. 
Table.1 The amount of construction waste recycling of construction sites

\begin{tabular}{|c|c|c|c|c|c|c|}
\hline The amount of construction & \multicolumn{7}{|c|}{ Construction sites } \\
\cline { 2 - 7 } waste recycling & $H_{1}$ & $H_{2}$ & $H_{3}$ & $H_{4}$ & $H_{5}$ & $H_{6}$ \\
\hline$A_{\mathrm{h}}$ & 115 & 150 & 140 & 69 & 50 & 50 \\
\hline
\end{tabular}

Table.2 The recycling amount of recycling center

\begin{tabular}{|c|c|c|c|c|r|}
\hline \multirow{2}{*}{ Recycling amount } & \multicolumn{5}{|c|}{ Recycling center } \\
\cline { 2 - 6 } & $I_{1}$ & $I_{2}$ & $I_{3}$ & $I_{4}$ & $I_{5}$ \\
\hline MAX- $U_{\mathrm{i}}$ & 130 & 140 & 175 & 190 & 168 \\
\hline
\end{tabular}

Table.3 The processing ability of detection processing center

\begin{tabular}{|c|c|c|c|}
\hline \multirow{2}{*}{$\begin{array}{c}\text { Treatment } \\
\text { capacity }\end{array}$} & \multicolumn{3}{|c|}{ Detection processing center } \\
\cline { 2 - 4 } & $J_{1}$ & $J_{2}$ & $J_{3}$ \\
\hline MAX- $V_{\mathrm{i}}$ & 180 & 190 & 170 \\
\hline
\end{tabular}

Table 4 The processing ability of regenerative machining center

\begin{tabular}{|c|c|c|c|c|}
\hline Processing & \multicolumn{4}{|c|}{ Regenerative machining center } \\
\cline { 2 - 5 } ability & $K_{1}$ & $K_{2}$ & $K_{3}$ & $K_{4}$ \\
\hline MIN-W $W_{\mathrm{k}}$ & 50 & 60 & 45 & 30 \\
\hline
\end{tabular}

Table.5 The unit transport costs from construction sites to recycling center

\begin{tabular}{|c|c|c|c|c|c|c|}
\hline \multirow{2}{*}{$\begin{array}{c}\text { Recycling } \\
\text { center }\end{array}$} & \multicolumn{7}{|c|}{ Construction sites } \\
\cline { 2 - 7 } & $H_{1}$ & $H_{2}$ & $H_{3}$ & $H_{4}$ & $H_{5}$ & $H_{6}$ \\
\hline$I_{1}$ & 5 & 10 & 8 & 12 & 20 & 9 \\
\hline$I_{2}$ & 10 & 5 & 6 & 4 & 32 & 16 \\
\hline$I_{3}$ & 18 & 12 & 24 & 8 & 6 & 15 \\
\hline$I_{4}$ & 6 & 16 & 11 & 14 & 12 & 8 \\
\hline$I_{5}$ & 30 & 25 & 20 & 14 & 16 & 6 \\
\hline
\end{tabular}

Table.6 The unit transport costs from recycling center to detection processing center

\begin{tabular}{|c|c|c|c|c|c|}
\hline \multirow{2}{*}{$\begin{array}{c}\text { Detection } \\
\text { processing center }\end{array}$} & $I_{1}$ & $I_{2}$ & $I_{3}$ & $I_{4}$ & $I_{5}$ \\
\hline$J_{1}$ & 15 & 8 & 6 & 12 & 10 \\
\hline$J_{2}$ & 10 & 10 & 8 & 14 & 18 \\
\hline$J_{3}$ & 12 & 14 & 20 & 16 & 8 \\
\hline
\end{tabular}

Table.7 The unit transport costs from detection processing center to regenerative machining center

\begin{tabular}{|c|c|c|c|}
\hline \multirow{2}{*}{$\begin{array}{c}\text { Regenerative } \\
\text { machining center }\end{array}$} & \multicolumn{3}{|c|}{ Detection processing center } \\
\cline { 2 - 4 } & $J_{1}$ & $J_{2}$ & $J_{3}$ \\
\hline$K_{1}$ & 16 & 12 & 20 \\
\hline$K_{2}$ & 8 & 14 & 9 \\
\hline$K_{3}$ & 20 & 14 & 8 \\
\hline$K_{4}$ & 4 & 10 & 14 \\
\hline
\end{tabular}

Table.8 Other costs related to recycling center

\begin{tabular}{|c|c|c|c|c|c|}
\hline \multirow{2}{*}{ Cost } & \multicolumn{5}{|c|}{ Recycling center } \\
\cline { 2 - 6 } & $I_{1}$ & $I_{2}$ & $I_{3}$ & $I_{4}$ & $I_{5}$ \\
\hline$C_{\mathrm{i}}$ & 12000 & 20000 & 120000 & 150000 & 100000 \\
\hline$O C_{\mathrm{i}}$ & 6 & 8 & 10 & 5 & 10 \\
\hline$V_{\mathrm{i}}$ & 18 & 20 & 11 & 12 & 16 \\
\hline
\end{tabular}

Table.9 Other costs related to detection processing center

\begin{tabular}{|c|c|c|c|}
\hline \multirow{2}{*}{ Cost } & \multicolumn{3}{|c|}{ Detection processing center } \\
\cline { 2 - 4 } & $J_{1}$ & $J_{2}$ & $J_{3}$ \\
\hline$C_{\mathrm{i}}$ & 320000 & 210000 & 240000 \\
\hline$O C_{\mathrm{i}}$ & 5 & 6 & 8 \\
\hline$V_{\mathrm{i}}$ & 15 & 10 & 20 \\
\hline$L C_{\mathrm{j}}$ & 12 & 15 & 24 \\
\hline
\end{tabular}

Table.10 Other costs related to regenerative machining center

\begin{tabular}{|c|c|c|c|c|}
\hline \multirow{2}{*}{ Cost } & \multicolumn{4}{|c|}{ Regenerative machining center } \\
\cline { 2 - 5 } & $K_{1}$ & $K_{2}$ & $K_{3}$ & $K_{4}$ \\
\hline$C_{\mathrm{k}}$ & 15000 & 12000 & 120000 & 150000 \\
\hline$O C_{\mathrm{k}}$ & 20 & 15 & 8 & 6 \\
\hline$V_{\mathrm{k}}$ & 12 & 15 & 7 & 10 \\
\hline
\end{tabular}




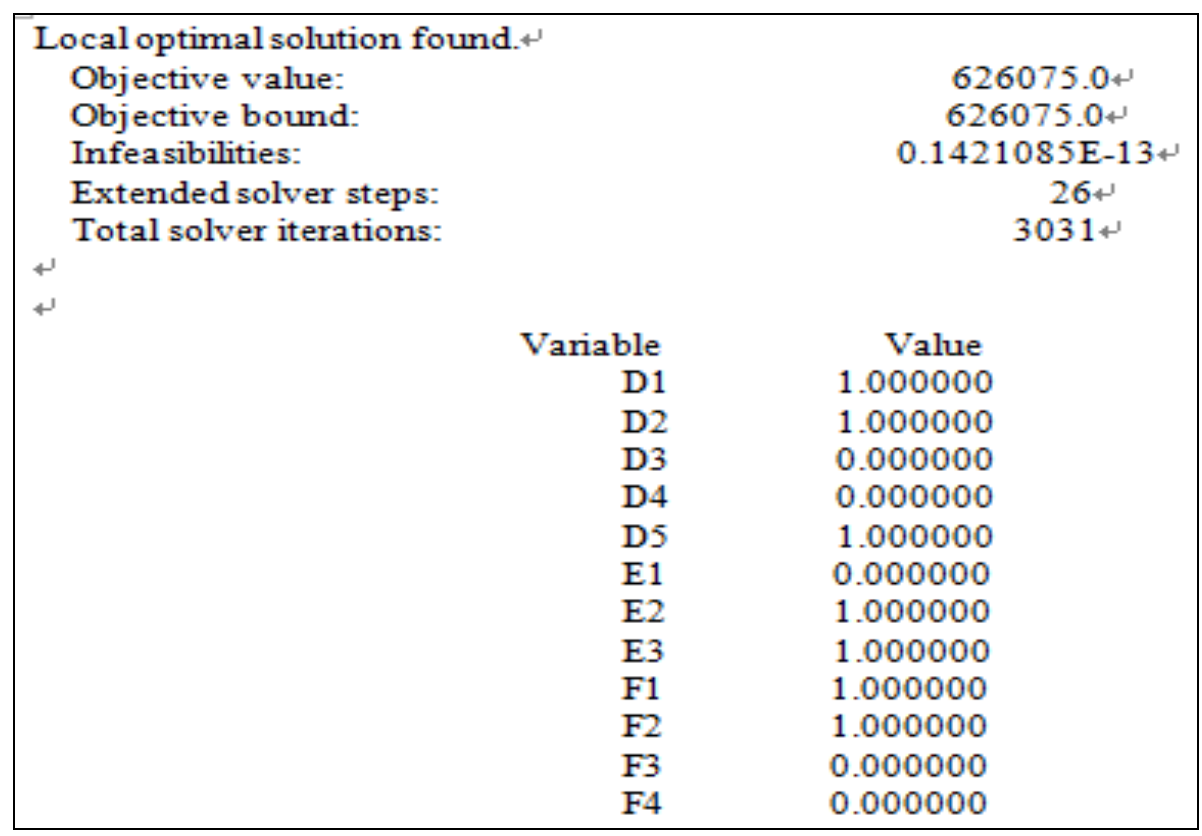

Fig.2. The simulation calculation results

\section{Conclusion}

This paper constructed a reverse recycling network based on the original building materials logistics. The network relates to three facilities about recycling center, detection processing center and regenerative machining center, considered the fixed investment cost, variable operating costs, unit cost of processing and transport cost, proposed a mixed integer programming model (MILP), and given specific examples and simulation method, realized the goal of minimum total cost.

However, because the construction waste reverse logistics involves a wide range, complicated influence factors and has the characteristics of randomness, therefore, in the planning of the actual problem, besides considering the principle of the lowest cost, should also consider environmental factors and other special requirements, further research also can consider to solve the uncertainty problem of construction waste reverse recycling.

\section{References}

[1] Shuai Cao, Yanling Shi. Discussion on the status and recycling management of construction waste [J]. Resource Saving and Environmental Protection, 11 (2013) 53.

[2] Xiuyu Li. Construction waste "turning waste into treasure" [N]. Shenzhen Commercial Daily, 2014-4-7(A01).

[3] Xiang Du. Study of building solid waste reverse logistics based on circular economy [D]. Hubei: Wuhan Science and Technique University, Master degree thesis (2012).

[4] Jingru Li, Xuming Mi, Zhikun Ding, Zhenrong Lin. Investigation on Generation and Disposal of Construction Waste on Site [J]. Ecological Economy, 4 (2011) 105-108.

[5] Peng Song. Regeneration practice of construction waste[A]. The Tenth International Conference on Green and Energy-Efficient Building [C]. 2014. 